\title{
Detection Rate of Thyroid Papillary Micro-carcinoma in Multinodular Goiter Surgery
}

\author{
Bahri Ozer1, Mustafa Sit1, Gulali Aktas², Fatih Keyif1, Ferdi Bolat1, Hayri Erkol1
}

\begin{abstract}
Objective: To determine the frequency of papillary thyroid micro-carcinoma (PTMC) in multinodular goiter (MNG) surgery, as well as in opposite thyroid lobule of the dominant nodule.

Study Design: Descriptive study.

Place and Duration of Study: General Surgery Department, Abant Izzet Baysal University Hospital, between January 2010 and December 2016.

Methodology: The data of 1300 patients who underwent thyroidectomy analyzed. Patients with single nodule in preoperative sonography, and patients with malignancy or suspected malignancy in fine needle aspiration cytology were excluded. PTMC was labelled as less than $10 \mathrm{~mm}$ in diameter.

Results: After exclusion of such patients, 1,197 subjects with benign MNG were included in the study. There were 1,134 patients in benign group and 63 subjects in PTMC group, according to the postoperative pathology results. In PTMC group, $53(84 \%)$ of subjects had one tumor and $10(16 \%)$ has more than one cancerous nodules. Thirty-six $(57 \%)$ of cancers in PTMC group were right sided and $27(43 \%)$ were left sided. Cancer and dominant nodule were in the same thyroid lobe in $62 \%(n=39)$ subjects in PTMC group. However, 24 subjects had cancer in the lobe opposite to the largest nodule.

Conclusion: Total bilateral thyroidectomy should be preferred in MNG surgery due to high probability of multicentric disease.
\end{abstract}

Key Words: Papillary thyroid micro-carcinoma, Thyroidectomy, Multicentric, Multinodular goiter.

\section{INTRODUCTION}

Thyroid diseases is increasing day by day in general population, due to the increased awareness for all diseases and technological developments in medicine. Multinodular goiter (MNG), which has a distinct place in thyroid diseases, has one place in itself. One of the most important problems for MNG patients is the possible cancer risk of one or more nodules. In addition, many studies reported detection of cancer in histopathological examination of postoperative thyroid tissue after MNG surgery. The cancer rate in such MNG surgeries was reported as high as 3-16,6\%.1,2

The vast majority of thyroid cancers are papillary cancers and micropapillary cancers which physicians and surgeons encountered more and more in postoperative pathology, have a distinct place in papillary thyroid cancer cases. Papillary thyroid carcinoma (PTC) less than $10 \mathrm{~mm}$ in diameter is called papillary thyroid micro-carcinoma (PTMC). Frequency of PTMC is about $4,7-9,9 \%$ in autopsy series. 3,4 Despite the name 'micro' in PTMC, lymph node recurrence, distant metastasis

Department of General Surgery ${ }^{1}$ / Internal Medicine ${ }^{2}$, Abant Izzet Baysal University Hospital, Bolu, Turkey

Correspondence: Dr. Bahri Ozer, Department of General Surgery, Abant Izzet Baysal University Hospital, Golkoy, 14280, Bolu, Turkey

E-mail: bahriozer@hotmail.com

Received: July 05, 2018; Accepted: November 03, 2018 and mortality has been reported in literature. ${ }^{5}$ Hence, its detection implies the risk of a potentially aggressive course.

The aim of the present study was to determine PTMC frequency in MNG surgery, and determine its presence in the thyroid lobe opposite to the dominant nodule.

\section{METHODOLOGY}

Data of 1,300 patients who underwent thyroidectomy between January 2010 and December 2016 in General Surgery Department, Abant Izzet Baysal University Hospital was retrospectively analyzed, after obtaining approval from Institutional Directory Board. Clinical and radiological records of all patients, especially thyroid sonography, laboratory tests and fine needle aspiration cytology (FNAC) results were evaluated. Patients with single nodule in preoperative USG, or over suspicious malignancy in FNAC were excluded from the study. After exclusion of such patients, 1,197 subjects with benign MNG were included to the study.

Bilateral total thyroidectomy and unilateral total thyroidectomy operation was performed for MNG patients. Patients were divided into two groups according to postoperative pathology results: Benign group and PTMC group.

The demographic parameters, pathology findings, and treatment results of all patients were recorded and statistically analyzed by SPSS software (SPSS 15.0 for Windows, IBM Inc, Chicago, IL, USA). Comparison of 
the non-homogenously distributed quantitative variables in study groups were compared by Mann-Whitney U-test and expressed as median (IQR) and qualitative variables were conducted by Chi-Square test and expressed as $n(\%)$. A p-value less than 0.05 was considered as statistically significant.

\section{RESULTS}

There were 1,134 patients in the benign group and 63 subjects in PTMC group, according to the postoperative pathology results. The median age of benign and PTMC groups were 50 (19) years and 47 (17) years, respectively. Age was not significantly different between study groups $(p=0.28)$. The diameter of largest nodule in benign and PTMC groups were 29 (4) $\mathrm{mm}$ and 29 (4) $\mathrm{mm}$, respectively. Largest nodule diameter was not significantly different between study groups. The difference was not significant.

Among the surgical procedures performed, 1,065 (94\%) who underwent bilateral total thyroidectomy were in benign group and 60 (95\%) were in PTMC group. Sixtynine $(6 \%)$ of unilateral total thyroidectomy procedures were performed in benign group and $3(4 \%)$ in PTMC group. Five hundred and eighty-one (51\%) of largest nodule in preoperative thyroid sonography was right sided and $553(49 \%)$ were left sided in benign group. On the other hand, largest nodule was right sided in 34 $(54 \%)$ and left sided in $29(46 \%)$ of PTMC patients. There was no statistically significant difference between the groups in terms of dominant nodule localization $(p=0.67)$.

In the PTMC group, 53 (84\%) of subjects had one tumor and $10(16 \%)$ has more than one cancerous nodules. Thirty-six $(57 \%)$ of cancers in PTMC group were right sided and $27(43 \%)$ were left sided. Cancer and dominant nodule were in the same thyroid lobe in $62 \%$ $(n=39)$ subjects in PTMC group. However, 24 subjects had cancer in the lobe opposite to the largest nodule placed.

\section{DISCUSSION}

Although all thyroid nodules were carefully evaluated for possible cancer in MNG, clinicians paid particular attention to the dominant nodule in follow-up of benign multinodular thyroid diseases. Accumulating evidence suggests that cancer risk in MNG disease is not insignificant. Fortunately, prognosis of thyroid cancer, especially differentiated cancers, is better. Recent studies emphasized that thyroidectomy specimens may contain multifocal nodules of PTMC. ${ }^{6}$

Goiter is the second most common endocrine disease affecting $5-7 \%$ of general population. 7,8 Surgical treatment is eventually needed in $10-15 \%$ of MNG cases, and MNG recurrence accounts for $12 \%$ of all thyroid operations.9,10 The rate of incidental thyroid malignancies in postoperative histopathological examination of thyroid surgery material is about 3-16.6\%.1,2 Erbil et al. reported thyroid cancer in $11 \%$ of patients that undergone surgery for benign MNG. ${ }^{11}$ The frequency of papillary thyroid microcarcinoma in autopsy series ranged between 4.7 - 9.9\%.3.4 Aside being a micro-carcinoma, another issue about papillary thyroid tumor is multicentric nature of such neoplasms. As a multicentric disease, more than one nodules may be tumoral in the same or opposite thyroid nodule in PTMC cases. Multicentricity in PTMC has been reported as high as $9.5-24.9 \%$ in recent studies. ${ }^{12,13}$ In the present study, PTMC was detected in $5.3 \%$ of the patients who were diagnosed with benign MNG disease. Interestingly, rate of multicentric disease in PTMC cases was $16 \%$ in present study. Everything aside, perhaps, the most important result of our study is the location of PTMC was in the opposite thyroid lobe of dominant nodule. Similarly, Karakose et al. reported a case with multicentric papillary carcinoma; however, in the same nodule, not opposite. ${ }^{14}$

Papillary thyroid carcinomas can arise from multicentric foci. 15 Despite microscopic multicentricity of papillary tumors is common, large and visible multicentric tumor foci is a rare entity. ${ }^{6} \mathrm{~A}$ study reported that occult thyroid papillary carcinoma may be seen in about half of the cases operated for benign multinodular goiter. ${ }^{16}$ Moreover, there are reports that suggested total thyroidectomy in multinodular goiter patients in the sake of excluding the risk of multicentric occult thyroid cancer. 6

Results of present study indicate that all thyroid nodules should be evaluated for PTMC. Therefore, surgeons may consider observation of both thyroid nodules for occult micropapillary carcinomas. Retrospective design is a limitation of present study; however, a large study population makes these results important for current literature.

\section{CONCLUSION}

Total bilateral thyroidectomy should be preferred instead of unilateral total thyroidectomy in MNG surgery due to high probability of multicentric disease as well as in the opposite lobule.

\section{REFERENCES}

1. Prades JM, Dumollard JM, Timoshenko A, Chelikh L, Michel F, Estour B, et al. Multinodular goiter: Surgical management and histopathological findings. Eur Arch Otorhinolaryngol 2002; 259:217-21.

2. Miccoli P, Minuto MN, Galleri D, D'Agostino J, Basolo F, Antonangeli $L$, et al. Incidental thyroid carcinoma in a large series of consecutive patients operated on for benign thyroid disease. ANZ J Surg 2006; 76:123-6.

3. Ito Y, Uruno T, Nakano K, Takamura Y, Miya A, Kobayashi K, et al. An observation trial without surgical treatment in patients 
with papillary microcarcinoma of the thyroid. Thyroid 2003; 13: 381-7.

4. Kovács GL, Gonda G, Vadász G, Ludmány É, Uhrin K, Görömbey $Z$, et al. Epidemiology of thyroid microcarcinoma found in autopsy series conducted in areas of different iodine intake. Thyroid 2005; 15:152-7.

5. Chow SM, Law SC, Chan JK, Au SK, Yau S, Lau WH. Papillary microcarcinoma of the thyroid-prognostic significance of lymph node metastasis and multifocality. Cancer 2003; 98:31-40.

6. Nakazawa T, Kondo T, Tahara I, Kasai K, Inoue T, Oishi N, et al. Multicentric occurrence of multiple papillary thyroid carcinomas-HUMARA and BRAF mutation analysis. Cancer Med 2015; 4:1272-80.

7. Müller RJ, Heinert G, Spelsberg F. Surgery for recurrent goitre: its complications and their risk factors. Eur J Surg 2001; 167: 816-21.

8. Tunbridge W, Evered D, Hall R, Appleton D, Brewis M, Clark F, et al. The spectrum of thyroid disease in a community: The Whickham survey. Clin Endocrinol 1977; 7:481-93.

9. Torre G, Barreca A, Borgonovo G, Minuto M, Ansaldo GL, Varaldo $\mathrm{E}$, et al. Goiter recurrence in patients submitted to thyroid-stimulating hormone suppression: Possible role of insulin-like growth factors and insulin-like growth factor-binding proteins. Surgery 2000; 127:99-103.

10. Kraimps JL, Marechaud R, Gineste D, Fieuzal S, Metaye T,
Carretier M, et al. Analysis and prevention of recurrent goiter. Surg Gynecol Obstetr 1993; 176:319-22.

11. Erbil Y, Barbaros U, SalmaslloGlu A, Yanlk BT, Bozbora A, ÖzarmaGan S. The advantage of near-total thyroidectomy to avoid postoperative hypoparathyroidism in benign multinodular goiter. Langenbecks Arch Surg 2006; 391:567-73.

12. Lin JD, Kuo SF, Chao TC, Hsueh C. Incidental and nonincidental papillary thyroid microcarcinoma. Ann Surgical Oncol 2008; 15:2287.

13. Schönberger J, Marienhagen J, Agha A, Rozeboom S, Bachmeier $\mathrm{E}$, Schlitt $\mathrm{H}$, et al. CME: Papillary microcarcinoma and papillary cancer of the thyroid $\leq 1 \mathrm{~cm}$-modified definition of the WHO and the therapeutic dilemma. Nuklearmedizin 2007; 46:115-20.

14. Karakose M, Hasdemir O, Cakal E, Delibasi T. A rare coexistence of non-functional adrenocortical carcinoma and multicentric papillary thyroid microcarcinoma: A case report. J Med Case Rep 2013; 7:200.

15. Katoh R, Sasaki J, Kurihara H, Suzuki K, lida Y, Kawaoi A. Multiple thyroid involvement (intraglandular metastasis) in papillary thyroid carcinoma. Cancer 1992; 70:1585-90.

16. Vassiliou I, Tympa A, Arkadopoulos N, Nikolakopoulos F, Petropoulou T, Smyrniotis V. Total thyroidectomy as the single surgical option for benign and malignant thyroid disease: A surgical challenge. Arch Med Sci 2013; 9:74. 